\title{
Static Response of Steel-Concrete-Steel Sandwich Beam with Bi-Directionally Inclined Connectors
}

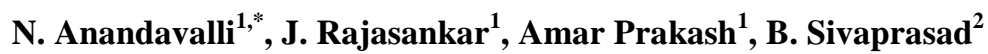 \\ ${ }^{1}$ Shock and Vibration Group, CSIR - Structural Engineering Research Centre, Chennai, India \\ ${ }^{2}$ L\&T Construction, Chennai, India \\ *Corresponding author: anandi@serc.res.in
}

Received December 28, 2012; Revised January 23, 2013; Accepted February 28, 2013

\begin{abstract}
Steel-concrete-steel (SCS) sandwich construction combines the advantages of both steel and concrete and finds application in numerous areas such as bridges, protection against impact and blast loads, flooring system etc. Shear connector is a critical component of SCS system. In the present study, two new configurations of bidirectionally inclined shear connector are proposed. Response behaviour of SCS beams with bi-directionally inclined connector is obtained through numerical investigations. Finite element models of SCS beams are generated by using a simplified approach that employs solid, plate and beam elements to represent concrete, cover plates and shear connector respectively. Behaviour of concrete is represented using concrete damaged plasticity model, while steel behaviour is modelled by using bilinear stress-strain curve. Beam is simply supported and is subjected to a central concentrated load. Nonlinear static analysis is carried out to obtain load-deflection response. Numerical model is validated by solving a SCS beam with through-through connectors, which was experimentally investigated in literature. Responses from bi-directionally inclined connectors are compared with that of through-through connectors. Bi-directionally inclined connector is found to be more ductile compared to that of through-through connector, while the load carrying capacity remains same. Parametric study is carried out by varying the cover plate thickness, angle of inclination and diameter of the connector to study their influence on the behaviour of the steelconcrete composite beam.
\end{abstract}

Keywords: steel-concrete-steel sandwich beam, bi-directionally inclined, shear connector, load-displacement

\section{Introduction}

Steel-concrete-steel (SCS) sandwich system consists of a concrete core sandwiched between two thin steel cover plates [1,2,3]. Transfer of forces between steel and concrete takes place through mechanical means called shear connectors. Therefore, performance of SCS sandwich system depends upon the efficiency of the shear connector. There are different types of shear connectors used in steel-concrete composite construction. Among these, conventional headed stud connector and throughthrough connectors are commonly used in steel-concretesteel sandwich construction. Resistance of face plates against tensile separation depends on pull out strength of headed studs in conventional headed stud connectors $[4,5]$. Steel plates and through-through shear connectors are fabricated in factory and concreting is done at site, thus facilitating ease of construction [6,7].

Double-skin composite (DSC) beams with mechanical shear connectors in the form of welded studs were experimentally investigated by Oduyemi and Wright [4]. These beams were found to display very good flexural characteristics in terms of their ultimate strength and ductility. Experimental studies were conducted by Wright et al. [5] on DSC elements formed from two steel skins connected to an infill of concrete with welded stud connectors. Structural behaviour of these elements was observed to be similar to doubly reinforced concrete elements in many respects, except for possibility of steel plate buckling and flexibility of plate to concrete connection. Shear connectors also gave rise to more discrete cracking in DSC elements subjected to flexural loading. Wright et al. [8] proposed design rules from the basic behaviour established through tests on model scale specimens of DSC elements. Wright et al. [9] presented a closed form solution for the analysis of simply-supported double skin composite beams, taking into account the flexibility of connection. The methods also covered the effects of concrete cracking and non-linear connector behaviour using a step-wise linearisation technique.

Bi-Steel is a system of double skin steel-concrete-steel construction. Units comprise of steel plates connected by an array of transverse friction welded shear connectors and filled with concrete [6,7]. Experimental and numerical studies on shear strength of Bi-steel connection subjected to push out load were carried out by Clubley et al. [10,11]. Studies indicated that Bi-steel system has significant shear capacity, which is affected by several parameters including plate spacing, connector spacing and shear connector diameter. For thick steel plates with small number of shear connector, the failure was found to be brittle. For thin plates, the failure was observed to be ductile, with a tear developing in the plate around the weld following large localised deformation of the plate. Use of 
numerical modelling has provided data which confirmed that panel behaviour was a function of panel geometry.

Experimental investigation on the static behaviour of steel-concrete composite beams with $\mathrm{Bi}$-steel connectors was carried out by Xie et al. [12]. Eighteen beams having a range of span, depth, plate shear, bar tension and concrete shear were tested. Four elementary modes of failure observed were tension plate failure, bar tension failure, concrete shear failure and bar shear failure. Liew and Sohel [13] proposed a new concept for designing composite structures comprising of lightweight concrete core sandwiched between two steel plates which are interconnected by J-hook connectors. Push-out tests confirmed that shear transfer capability of J-hook connector was found to be superior than conventional headed stud connector in achieving composite action between steel plate and concrete core. Liew et al. [14] studied impact performance of SCS sandwich beams consisting of a lightweight concrete core sandwiched between two face plates that are connected by J-hook connectors. Impact tests were carried out by dropping free weights on to sandwich beams to investigate their structural response against impact loads. Test results revealed that $\mathrm{J}$-hook connectors provide an effective means to interlock top and bottom steel face plates, preventing them from separation during impact. A numerical parametric study was conducted by Li et al [15] to investigate behaviour of steel-concrete composite (SCC) beam under localised blast loading. It is found that under a localised blast load, SCC beam failed mainly in three failure modes, namely, local concrete damage, flexural failure and punching shear failure. Punching shear failure is a brittle failure mode and should be avoided in the design of SCC beam against localised blast loading. Longterm behaviour of composite steel concrete beams with partial interaction was presented by Al-deen et al [16]. Considerable increase in beam deflection was observed due to concrete creep and shrinkage in all beams. Further, influence of time effects on ultimate response of SCC beam was studied by Al-deen et al. [17].

In this paper, response behaviour of steel-concrete-steel beams with two new configurations of bi-directionally inclined shear connector subjected to central concentrated load is numerically simulated using finite element analysis. Numerical model is generated using a simplified approach, which is validated with an example problem from literature. Displacement responses of SCS beams with proposed bi-directionally inclined connectors are compared with that of SCS beam with through-through connectors. Configuration with enhanced performance is chosen for parametric study. Thickness of cover plate, spacing, diameter and angle of inclination of shear connector are the parameters considered to study their influence on deflection response of the beam.

\section{Numerical Model}

Finite element model of SCS beams are generated using a simplified approach. In this approach, concrete, steel cover plates and connector are modelled using solid, shell and beam elements respectively. Plates are meshed using linear quadrilateral elements, while concrete core is meshed using linear hexahedral elements. Shear connectors are meshed using linear elements. In this model, connectors and steel plates are connected by welded connection. Connection of weld provides a fully bonded connection between two nodes. Connectors are embedded in concrete, which will effectively transfer shear by bond action. Embedded element technique is used to specify an element or a group of elements that lie embedded in a group of host elements, whose response will be used to constrain translational degrees of freedom of embedded nodes (i.e., nodes of embedded elements).

Concrete damaged plasticity model is used for representing concrete behaviour. Compressive stressstrain curve of concrete proposed by Attard and Setunge [18], which has been shown to be applicable to a broad range of in situ concrete strength from 20 to $130 \mathrm{MPa}$, is adopted in FE analysis. In this model, parameters used to establish stress-strain curve are initial Young's modulus $\mathrm{E}_{\mathrm{c}}$, peak compressive stress $\mathrm{f}_{\mathrm{co}}$ and corresponding strain $\varepsilon_{\mathrm{co}}$, and compressive stress $\mathrm{f}_{\mathrm{ci}}$ and strain $\varepsilon_{\mathrm{ci}}$ at the inflection point on descending branch of the curve. Figure 1 shows the stress-strain behaviour of concrete. Under compression, stress in concrete, $\sigma_{\mathrm{c}}$ is related to strain in concrete, $\varepsilon_{\mathrm{c}}$ by

$$
\frac{\sigma_{\mathrm{c}}}{\mathrm{f}_{\mathrm{co}}}=\frac{\mathrm{A}\left(\varepsilon_{\mathrm{c}} / \varepsilon_{\mathrm{co}}\right)+\mathrm{B}\left(\varepsilon_{\mathrm{c}} / \varepsilon_{\mathrm{co}}\right)^{2}}{1+(\mathrm{A}-2)\left(\varepsilon_{\mathrm{c}} / \varepsilon_{\mathrm{co}}\right)+(\mathrm{B}+1)\left(\varepsilon_{\mathrm{c}} / \varepsilon_{\mathrm{co}}\right)^{2}}
$$

where $\mathrm{A}$ and $\mathrm{B}$ are coefficients dependent on concrete grade.

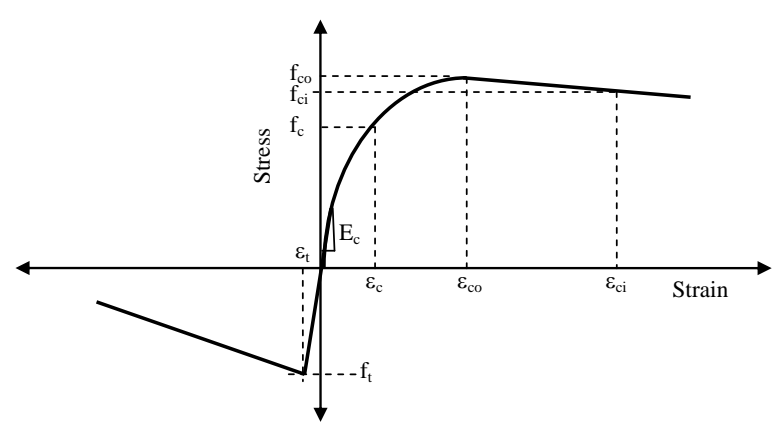

Figure 1. Stress-strain behaviour of concrete

Two sets of coefficients $\mathrm{A}$ and $\mathrm{B}$ are required, with one for ascending branch and another for descending branch of the curve. For ascending branch, where $\varepsilon_{\mathrm{c}} \leq \varepsilon_{\mathrm{co}}$, coefficients $\mathrm{A}$ and $\mathrm{B}$ are given by

$$
\begin{gathered}
A=\frac{E_{c} \varepsilon_{c o}}{f_{c o}} \\
B=\frac{(A-1)^{2}}{0.55}-1
\end{gathered}
$$

For descending branch, where $\varepsilon_{\mathrm{c}}>\varepsilon_{\mathrm{co}}$, coefficients A and $\mathrm{B}$ are given by

$$
\begin{gathered}
A=\frac{\mathrm{f}_{\mathrm{ci}}\left(\varepsilon_{\mathrm{ci}}-\varepsilon_{\mathrm{co}}\right)^{2}}{\varepsilon_{\mathrm{co}} \varepsilon_{\mathrm{ci}}\left(\mathrm{f}_{\mathrm{co}}-\mathrm{f}_{\mathrm{ci}}\right)} \\
\mathrm{B}=0
\end{gathered}
$$

Parameters $\mathrm{E}_{\mathrm{c}}, \varepsilon_{\mathrm{co}}, \mathrm{f}_{\mathrm{ci}}$ and $\varepsilon_{\mathrm{ci}}$ are theoretically related to $f_{\text {co }}$ by: 


$$
\begin{gathered}
\mathrm{E}_{\mathrm{c}}=4370\left(\mathrm{f}_{\mathrm{co}}\right)^{0.52} \\
\varepsilon_{\mathrm{co}}=4.11\left(\mathrm{f}_{\mathrm{co}}\right)^{0.75} / \mathrm{E}_{\mathrm{c}} \\
\mathrm{f}_{\mathrm{ci}} / \mathrm{f}_{\mathrm{co}}=1.41-0.17 \ln \left(\mathrm{f}_{\mathrm{co}}\right) \\
\varepsilon_{\mathrm{ci}} / \varepsilon_{\mathrm{co}}=2.50-0.30 \ln \left(\mathrm{f}_{\mathrm{co}}\right)
\end{gathered}
$$

In the present study, model proposed by Guo and Zhang [19] is adopted for post-cracking resistance in tension. In this model, compressive stress in concrete, $\sigma_{\mathrm{c}}$ is related to tensile strength $\mathrm{f}_{\mathrm{t}}$ by the following expression:

$$
\frac{\sigma_{\mathrm{c}}}{\mathrm{f}_{\mathrm{t}}}=\frac{-\varepsilon_{\mathrm{c}} / \varepsilon_{\mathrm{t}}}{\alpha\left(\varepsilon_{\mathrm{c}} / \varepsilon_{\mathrm{t}}-1\right)^{1.7}+\left(\varepsilon_{\mathrm{c}} / \varepsilon_{\mathrm{t}}\right)}
$$

where

$f_{t}$ is tensile strength of concrete

$\varepsilon_{t}$ is strain in concrete at tensile strength

$\alpha$ is a parameter dependent on concrete grade

Bilinear stress-strain curve as shown in Figure 2 is used for simulating steel behaviour of plates and connectors.

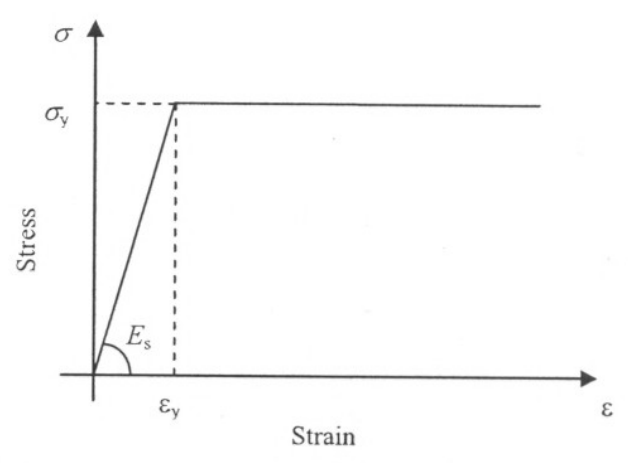

Figure 2. Bilinear material model

Simplified approach is validated by solving a SCS beam with through-through connectors available in literature [12]. Concrete is sandwiched between two steel plates: compression plate and tension plate of thicknesses $11.93 \mathrm{~mm}$ and $6.20 \mathrm{~mm}$ respectively. Beam is of $2200 \mathrm{~mm}$ length with effective span of $1800 \mathrm{~mm}$. Width of the beam is $400 \mathrm{~mm}$, while its depth $200 \mathrm{~mm}$. Through-through connectors of $25 \mathrm{~mm}$ diameter are spaced at $300 \mathrm{~mm} \mathrm{c} / \mathrm{c}$ and $200 \mathrm{~mm} \mathrm{c} / \mathrm{c}$ along length and width of the beam respectively. Beam is simply supported over a span of $1800 \mathrm{~mm}$. Concentrated load of magnitude $800 \mathrm{kN}$ is applied at mid span of the beam. Details of the beam are shown in Figure 3.

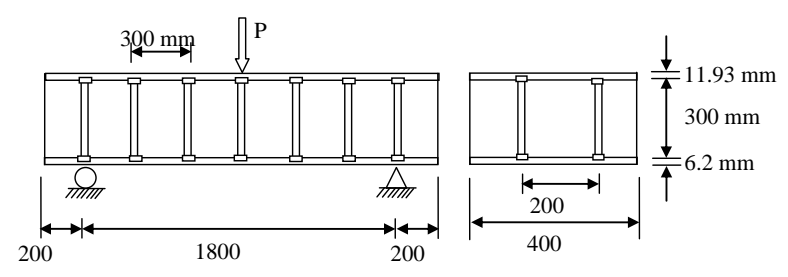

Figure 3. Experimental details of SCS beam

Finite element model of beam is generated using simplified approach as well as using solid elements. In solid model, all the components of SCS beam are discretised using solid elements. Linear hexahedral solid elements is used in this model. In this model, surface to surface interaction is used for interfaces between concrete and steel (connectors and plates). Steel cover plates with connectors modelled using solid elements and simplified approach are shown in Figure 4 and Figure 5 respectively. Yield strength of plate and connector are $384 \mathrm{MPa}$ and $541 \mathrm{MPa}$ respectively. Characteristic compressive strength of concrete is $40 \mathrm{MPa}$. Concrete damage plasticity is used to model concrete behaviour, while steel behaviour is simulated using bilinear material model. Non linear static analysis is carried.

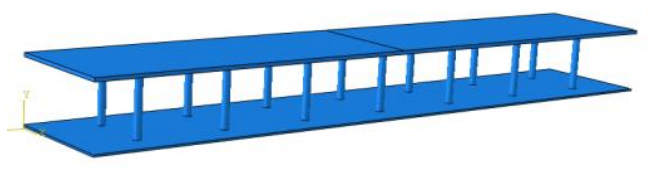

Figure 4. Solid model

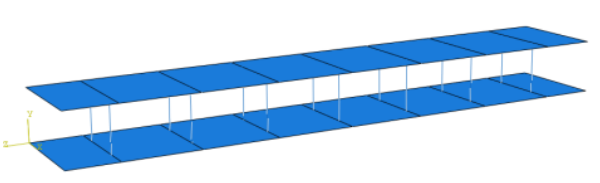

Figure 5. Simplified model

Load deflection response of beam at midspan is compared with experimental values and is shown in Figure 6. Response of simplified model is in good agreement in elastic region upto a load of $444 \mathrm{kN}$. After this, response is nonlinear similar to a trend observed in experimental load deflection response. Ultimate load predicted by simplified model is slightly higher than that of experimental value. Simplified approach used in this study has less computational demand than that of solid model, while response is predicted with a good level of accuracy.

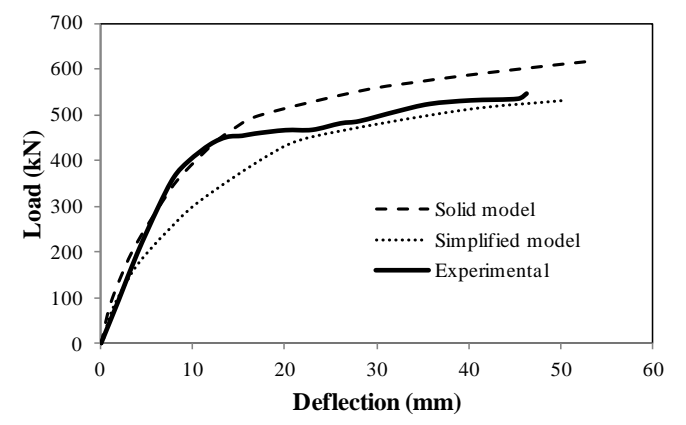

Figure 6. Load deflection response of experiment and numerical model

\section{Bi-Directionally Inclined Connectors}

Traditionally, shear transfer is carried out by stud connectors or by through-through connectors. Two new configurations of bi-directionally inclined shear connectors are proposed. They are truss and ' $\mathrm{X}$ ' configurations as shown in Figure 7. Diameter of inclined connectors is arrived at by equating the volume of connectors to that of through-through connectors. For truss configuration, vertical and inclined connectors are of $12 \mathrm{~mm}$ diameter, while for ' $\mathrm{X}$ ' configuration, diameters of vertical and inclined connectors are $12 \mathrm{~mm}$ and $8 \mathrm{~mm}$ respectively. Effective span of SCS beam is $1800 \mathrm{~mm}$. Concentrated load of magnitude $1600 \mathrm{kN}$ is applied at 
mid-span. Two rows of connectors are provided at spacing of $200 \mathrm{~mm} \mathrm{c} / \mathrm{c}$ in width direction. Material properties for both the beams are same as that of SCS beam with through-through connectors. Non-linear static analysis is carried out.

Load deflection responses of SCS beams are compared with that of through-through connectors. From Figure 8, truss configuration is found to be more ductile, but load carrying capacity remains same as that of through-through connector, where as ' $\mathrm{X}$ ' configuration is comparatively less ductile. Displacement response of truss configuration is found to be better and it has been used for parametric study.
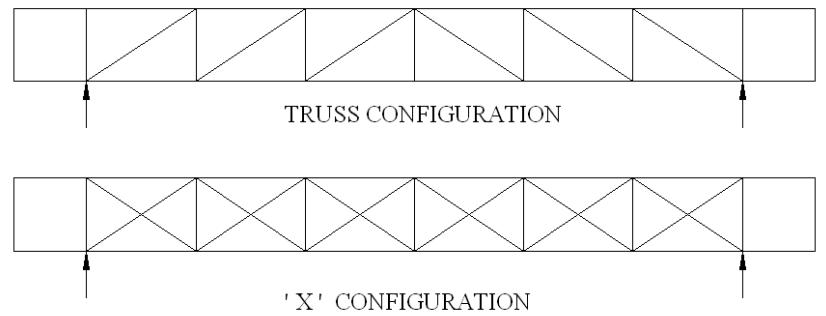

Figure 7. New configurations of bi-directionally inclined connectors

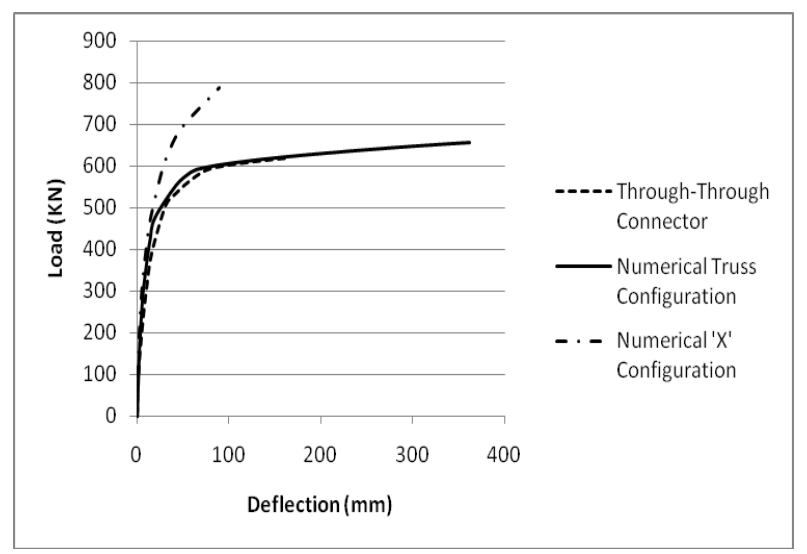

Figure 8. Load displacement response of truss and ' $\mathrm{X}$ ' configuration

\section{Parametric Study}

Parameters considered in this study are thickness of cover plate, angle and diameter of connectors and their values are given in Table 1. Effect of these parameters on displacement response of SCS sandwich beams with truss configuration is obtained.

Table 1. Parameters considered

\begin{tabular}{|c|c|}
\hline Parameter & Values \\
\hline Thickness of cover plate, $\mathrm{mm}$ & 8,10 and 12 \\
\hline Angle of inclination of connector & $34^{\circ}, 42^{\circ}, 48^{\circ}$ and $53^{\circ}$ \\
\hline $\begin{array}{c}\text { Spacing of connector corresponding } \\
\text { to angles of inclination, } \mathrm{mm}\end{array}$ & $150,180,225,300$ \\
\hline Diameter of connector, $\mathrm{mm}$ & $8,10,12$ and 16 \\
\hline
\end{tabular}

\subsection{Thickness of Cover Plate}

Thickness of cover plate is varied, keeping other parameters constant. Analysis is repeated for different angles and plate thicknesses. Figure 9, Figure 10, Figure 11 and Figure 12 show variation of displacement with plate thickness for $8 \mathrm{~mm}, 10,12$ and $16 \mathrm{~mm}$ diameters of connector respectively.

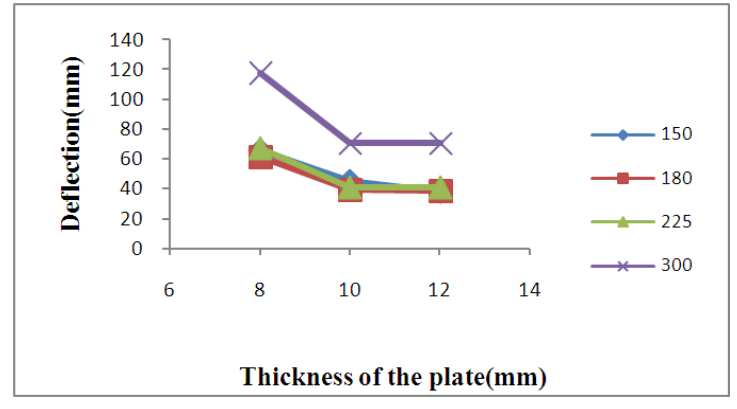

Figure 9. Variation of displacement with plate thickness (Diameter of connector - 8mm)

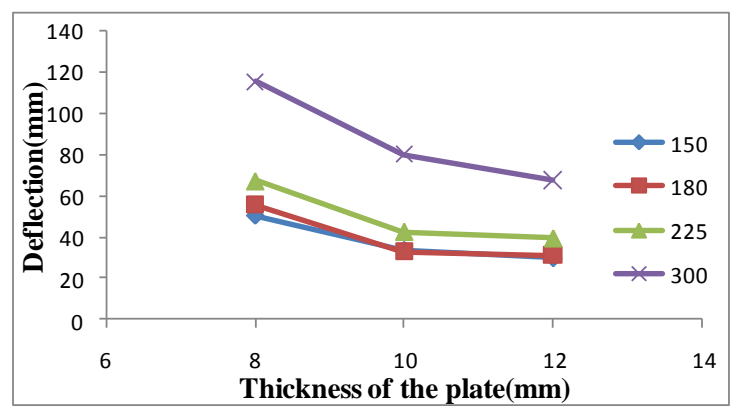

Figure 10. Variation of displacement with plate thickness (Diameter of connector $-10 \mathrm{~mm}$ )

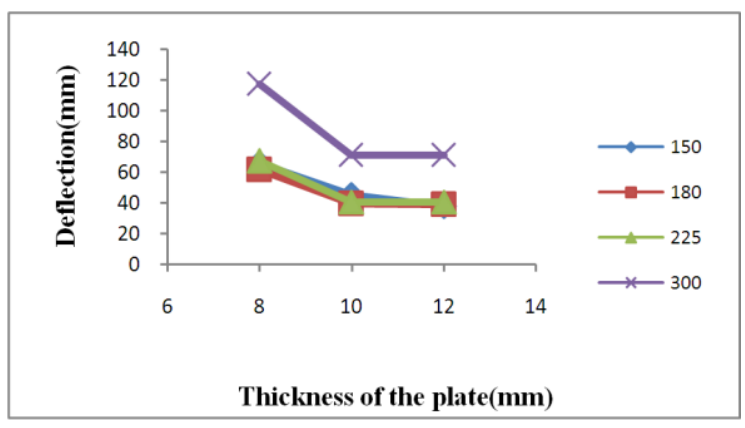

Figure 11. Variation of displacement with plate thickness (Diameter of connector $-12 \mathrm{~mm}$ )

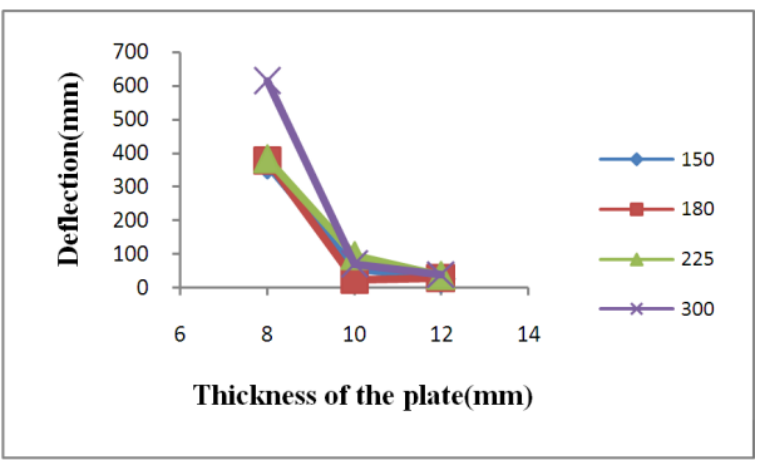

Figure 12. Variation of displacement with plate thickness (Diameter of connector - $16 \mathrm{~mm}$ )

As seen from the Figs. 9 to 12, it can be observed that displacement reduces with increase in plate thickness from $8 \mathrm{~mm}$ to $10 \mathrm{~mm}$. Beyond this, increase in plate thickness is found to have negligible influence in displacement response.

\subsection{Angle of inclination of connector}

Different angles of inclination and corresponding spacing of connectors are given in Figure 13. Thicknesses 
of compression and tension plates are 11.93 and $6.20 \mathrm{~mm}$ respectively. Diameter of connector is kept as $12 \mathrm{~mm}$. Nonlinear static analysis is performed for all four truss configurations.

A graph is plotted between angle of inclination with deflection and load as shown in Figure 14. Displacement of SCS beam decreases by about $29.5 \%$ with increase in angle of inclination, whereas there is only marginal influence of about $7 \%$ in load carrying capacity.

This analyses is repeated for other plate thicknesses. Figure 15 shows variation of displacement and maximum load with angle of inclination for various plate thicknesses. For spacing of connector less than $225 \mathrm{~mm}$, variation of spacing shows no effect on displacement for spacing of connector less than $225 \mathrm{~mm}$, after which displacement increases suddenly. This trend is observed for all plate thicknesses. It is clearly seen that load carrying capacity of SCS beam has marginal difference, when spacing of connectors is varied.
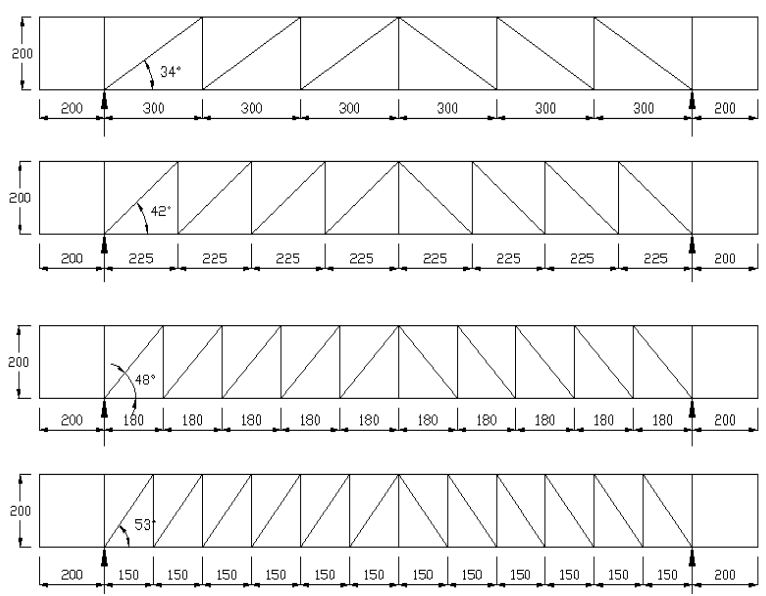

Figure 13. Variation in angle and spacing of connectors

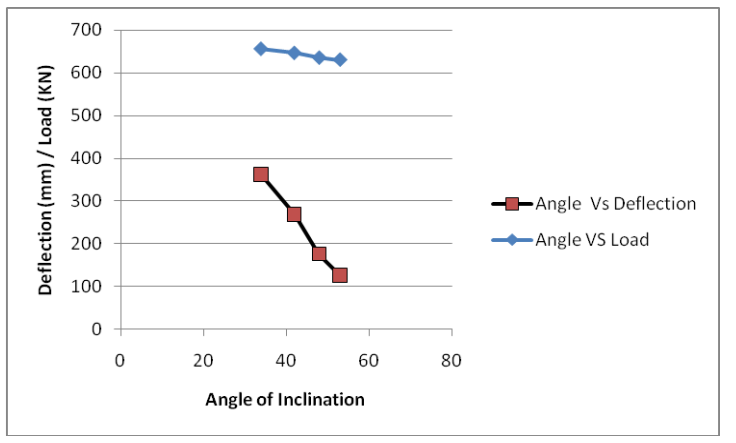

Figure 14. Load/deflection Vs angle of inclination

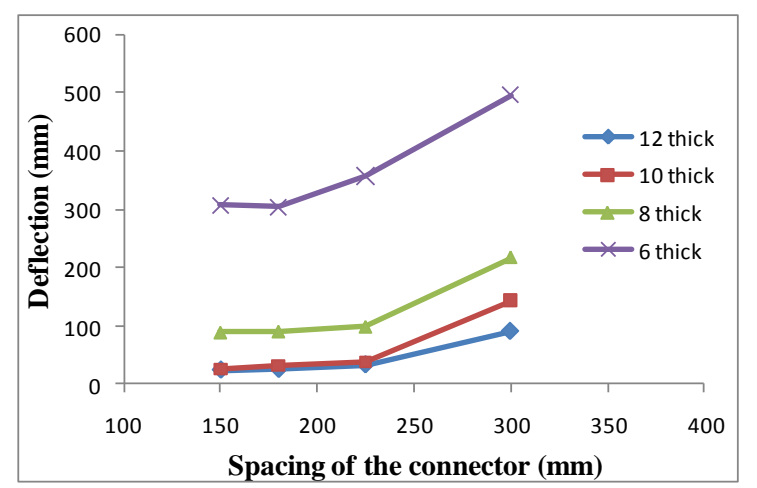

(a) Displacement

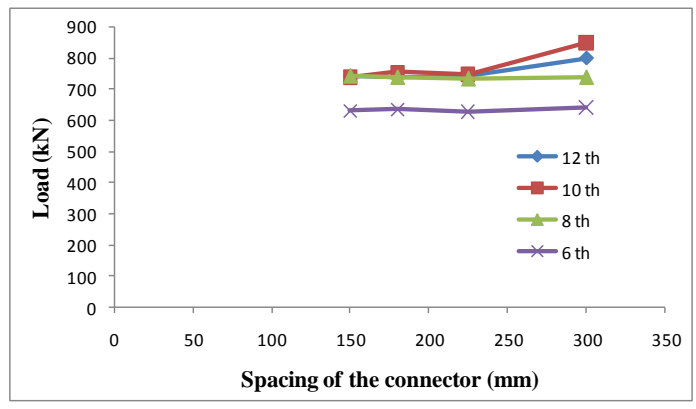

(b) Load

Figure 15. Influence of spacing of connector

\subsection{Diameter of connector}

Analysis is repeated by varying diameter of connector, keeping plate thickness and angle of inclination constant. This is repeated for different plate thickness and angles of inclination. Variation of displacement with diameter of connector for $150,180,225$ and $300 \mathrm{~mm}$ spacing of connectors are shown in Figure 16, Figure 17, Figure 18 and Figure 19 respectively.

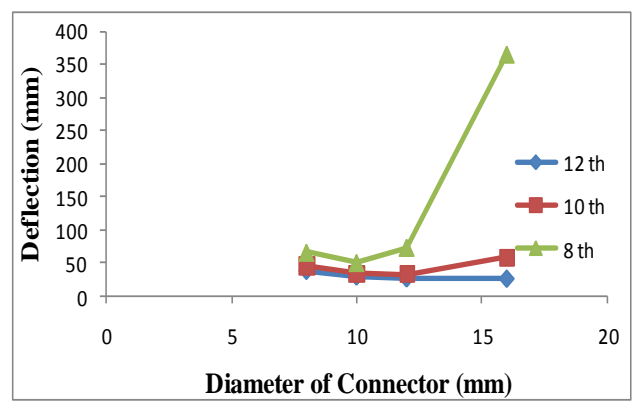

Figure 16. Variation of displacement with connector diameter (for 150 mm spacing)

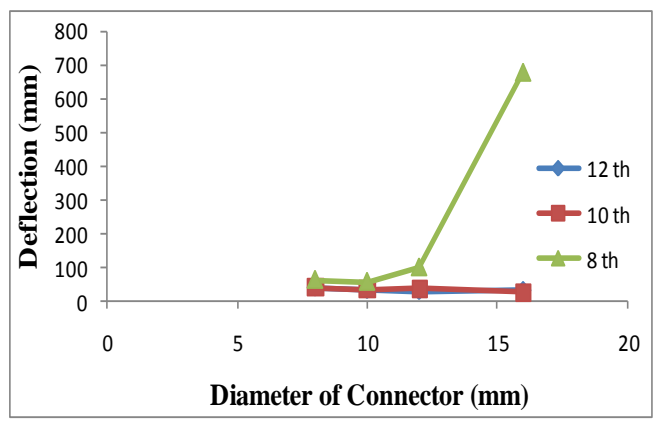

Figure 17. Variation of displacement with connector diameter (for 180 mm spacing)

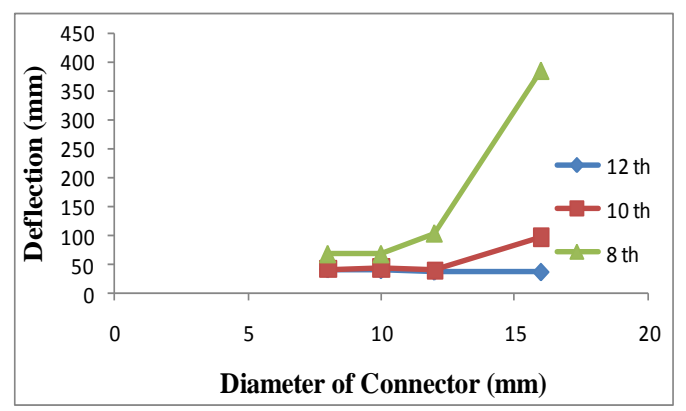

Figure 18. Variation of displacement with connector diameter (for 225 mm spacing) 


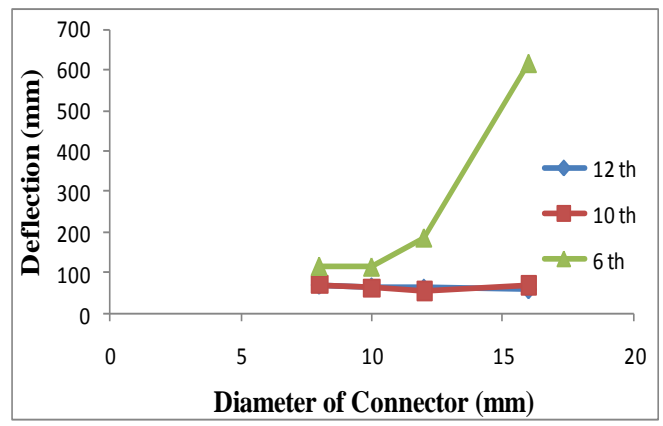

Figure 19. Variation of displacement with connector diameter (for 300 mm spacing)

From the above graphs, diameter of connector less than $12 \mathrm{~mm}$ is found to have negligible effect on displacement response. $16 \mathrm{~mm}$ diameter of connector has high deflection value, but practically it cannot be welded with less thick plates. Therefore, $12 \mathrm{~mm}$ diameter is found to be optimum.

\section{Conclusion}

Two new configurations of bi-directionally inclined connector are proposed in this paper. Truss configuration is found to be more ductile than ' $\mathrm{X}$ ' configuration. Angle of inclination of members in truss configuration is found to have more influence on displacement, while load carrying capacity changes only marginally. Angle of inclination between 40 to 50 degrees is found to be optimum and plate thickness of $10 \mathrm{~mm}$ and $12 \mathrm{~mm}$ diameter is found to perform better.

\section{Acknowledgement}

Paper is being published with kind permission of Director, CSIR-Structural Engineering Research Centre, Council of Scientific and Industrial Research.

\section{References}

[1] Sohel, K.M.A., Liew, J.Y.R., Alwis, W.A.M., Paramasivam, P., "Experimental investigation of low-velocity impact characteristics of steel-concrete-steel sandwich beams", Intl. Journal of Steel and Composite Structures, 3, 2003, 289-306.
[2] Qian, J., Jiang, Z., Ji, X., "Behavior of steel tube-reinforced concrete composite walls subjected to high axial force and cyclic loading”, Engineering Structures, 36 (3), 2012, 173-184.

[3] Chakrabarti, A., Sheikh, A.H., Griffith, M., Oehlers, D.J., "Analysis of composite beams with partial shear interactions using a higher order beam theory", Engineering Structures, 36 (3), 2012, 283-291.

[4] Oduyemi, T.O.S. and Wright, H.D., "An experimental investigation into the behaviour of double skin sandwich beams", Journal of Constructional Steel Research, 14 (3), 1989, 197-220.

[5] Wright, H.D., Oduyemi, T.O.S., Evans, H.R., "The experimental behaviour of double skin composite elements", Journal of Constructional Steel Research, 19 (2), 1991, 97-110.

[6] Bowerman, H.G., Gough, M.S., King, C.M., "Bi-Steel design and construction guide", British Steel Ltd, London: Scunthorpe; 1999.

[7] Bowerman, H., Coyle, N., Chapman, J.C., "An innovative steel/concrete construction system", Structural Engineering, 80, 2002, 33-38.

[8] Wright, H.D., Oduyemi, T.O.S., Evans, H.R., "The design of double skin composite elements", Journal of Constructional Steel Research, 19 (2), 1991, 111-132.

[9] Wright, H.D., and Oduyemi, T.O.S., "Partial interaction analysis of double skin composite beams", Journal of Constructional Steel Research, 19 (4), 1991, 253-283.

[10] Clubley, S.K., Moy, S.S.J., Xiao, R.Y., "Shear strength of steelconcrete-steel composite panels: Part I - testing and numerical modeling", Journal of Constructional Steel Research, 59 (6), 2003 781-794.

[11] Clubley, S.K., Moy, S.S.J., Xiao, R. Y., "Shear strength of steelconcrete-steel composite panels: Part II-detailed numerical modeling of performance", Journal of Constructional Steel Research, 59 (6), 2003, 795-808.

[12] Xie, M., Foundoukos, N., Chapman, C., "Static tests on steelconcrete-steel sandwich beams", Journal of Constructional Steel Research, 63(5), 2007, 735-750.

[13] Liew, J.Y.R., and Sohel, K.M.A., "Lightweight steel-concretesteel sandwich system with J-hook connectors", Engineering Structures, 31 (5), 2009, 1166-1178.

[14] Liew, J.Y.R., Sohel, K.M.A., Koh, C.G., "Impact tests on steelconcrete-steel sandwich beams with lightweight concrete core", Engineering Structures, 31 (9), 2009, 2045-2059.

[15] Li, G.Q., Yang, T.C., Chen, S.W., "Behavior and simplified analysis of steel-concrete composite beams subjected to localized blast loading", Structural Engineering and Mechanics, 32 (2), 2009, 337-350.

[16] Al-Deen, S., Ranzi, G., Vrcelj, Z. "Long-term Experiments of Composite Steel-Concrete Beams", Procedia Engineering, 14, 2011, 2807-2814.

[17] Al-Deen, S., Ranzi, G., Vrcelj, Z., "Full-scale long-term and ultimate experiments of simply-supported composite beams with steel deck", Journal of Constructional Steel Research, 67 (10), 2011, 1658-1676.

[18] Attard, M.M., and Setunge, S., "The stress-strain relationship of confined and unconfined concrete", ACI Materials Journal, 93 (5), 1996, 432-442.

[19] Guo, Z.H., and Zhang, X.Q., "Investigation of complete stressdeformation curves for concrete in tension", ACI Materials Journal, 84 (4), 1987, 278-285. 